\title{
Association between thyroid disorders and abnormal uterine bleeding in reproductive ages
}

\author{
Aiyleen S. Shawl ${ }^{1 *}$, Massarat $\mathrm{Naz}^{2}$ \\ ${ }^{1}$ Department of Obstetrics and Gynecology, L. D. Hospital, Srinagar, Jammu and Kashmir, India
${ }^{2}$ Private Consultant, Obstetrics and Gynecology, Srinagar, Jammu and Kashmir, India
}

Received: 28 July 2020

Accepted: 03 August 2020

*Correspondence:

Dr. Aiyleen S. Shawl,

E-mail: soulfulshiza@gmail.com

Copyright: () the author(s), publisher and licensee Medip Academy. This is an open-access article distributed under the terms of the Creative Commons Attribution Non-Commercial License, which permits unrestricted non-commercial use, distribution, and reproduction in any medium, provided the original work is properly cited.

\begin{abstract}
Background: Abnormal uterine bleeding (AUB) means any bleeding that is not normal in amount, duration, frequency, and cyclicity. It is a common disorder occurring in reproductive age group females. It can be understood as bleeding that occurs from the uterus outside the normal parameters and there are no structural defects in the genital tract. One of the most common associations with AUB is thyroid dysfunctions. Hence, this study aimed to see the incidence of thyroid-related disorders in AUB and also to assess the menstrual pattern.

Methods: A total 100 women suffering from AUB who presented to OPD of the gynecology department of L D Hospital Srinagar, Jammu and Kashmir were recruited in the study. All females in 19 to 45 years of age group with abnormal uterine bleeding were included excluding those with a previously known thyroid disorder, abortion history within 3 months, etc. Thyroid function tests were done in all along with ultrasonography of the pelvis region. Data were analyzed using SPSS software v.23.0. and Microsoft office 2007.

Results: The bleeding abnormality that was found in most of the women was heavy menstrual bleeding. Out of the 100 patients taken into study 11 had thyroid disorders, out of which subclinical hypothyroidism was most prevalent accounting for 8 cases, 2 cases were found to have hypothyroidism and 1 case of hyperthyroidism was detected.

Conclusions: Abnormal uterine bleeding has a strong association with thyroid disorders. The most common type of disorder is subclinical hypothyroidism. Thus, all patient of AUB must be evaluated for thyroid dysfunction.
\end{abstract}

Keywords: Abnormal uterine bleeding, Hypothyroidism, Hyperthyroidism, Menstrual cycle, Subclinical hypothyroidism, Thyroid disorders

\section{INTRODUCTION}

Abnormal uterine bleeding (AUB) means any bleeding that is not normal in amount, duration, frequency, and cyclicity. ${ }^{1}$ It is one of the frequent complaints of women attending gynecology clinics. It is seen in $15-20 \%$ of women from the commencement of menarche to menopause and has a great impact on the quality life of the women. ${ }^{2}$ The AUB is also affecting women in pre and postmenopausal age periods. ${ }^{3}$ It manifests in many forms like menorrhagia, metrorrhagia, menometrorrhagia, polymenorrhea, polymenorrhagia, and oligomenorrhea. ${ }^{4}$ One of the most common associations with AUB is thyroid dysfunctions. The causes of AUB might be related to hormonal balance disturbances or it might be a clinical presentation for benign or malignant lesions of the female genital tract in the reproductive age group woman.

Endocrinological dysfunctions, including thyroid disorders, plays a major role in its etiopathogenesis. Thyroid hormones exert multiple effects on the human body specifically on the development, metabolism, growth, and functions of major organ systems in the human body. ${ }^{5}$ Looking at its effects on reproductive age group females, thyroid dysfunction leads to AUB, 
infertility, delayed puberty recurrent miscarriages as well as premature menopause. ${ }^{6}$

The mechanism behind menstrual irregularities due to thyroid disorders may be multiple. The mechanism by which the thyroid disorders is associated with AUB may be explained by altering thyroid-stimulating hormone (TSH) response, increasing prolactin levels, altering luteinizing hormone (LH) response, affecting peripheral conversion of androgens to estrogens, altering sex hormone-binding globulin (SHBG) and affecting coagulation pathways in addition to the effect on lipid profile. $^{7}$

The hypothyroidism is a frequent cause of multiple disorders in women at reproductive age ranged from sexual dysfunction, menstrual abnormalities, and infertility. ${ }^{8}$ Irregularities in the menstrual cycle may accompany or precede with clinically overt hypothyroidism or hyperthyroidism. ${ }^{9}$ Many studies have proven that hypothyroidism is more commonly associated with hypothyroidism whereas anovulation or oligomenorrhoea common in those having hyperthyroidism. ${ }^{10,11}$

Disturbed cycles and abnormal blood flow are the first menstrual problems for women with hypothyroidism. ${ }^{12,13}$ The occult menorrhagia is an earlier presentation for women with subclinical hypothyroidism. ${ }^{14}$ The menstrual irregularity was the presenting symptom of $24 \%$ of Iraqi women diagnosed with hypothyroidism. ${ }^{15}$ Studies showed that $33.3 \%$ of patients with hypothyroidism had menorrhagia. ${ }^{16}$ The mechanism explained was it seems that poor progesterone production is associated with persistent endometrial proliferation which may be responsible for massive bleeding. Another, mechanism for this may be a failure of $\mathrm{LH}$ secretion. $44.4 \%$ of patients with hypothyroidism had oligomenorrhoea. This was explained by the galactorrhoea amenorrhoea syndrome in long-standing hypothyroid patients. ${ }^{17}$

In the above context, an attempt has been made to assess the association between thyroid disorders and abnormal uterine bleeding in reproductive ages to have more insight on the present situation and mechanism of association of thyroid disorders with AUB in the study area.

\section{METHODS}

It was a hospital-based cross-sectional descriptive type of observational study conducted at the OPD of the gynecology department of L. D. Hospital Srinagar. Cases were taken for consideration for the study between October 2019 to June 2020. 100 women who presented to the gynecology outpatient department with AUB were recruited in the study.

All females in 19 to 45 years of age group with abnormal uterine bleeding and those giving informed consent were included as subjects in the proposed study. The exclusion criteria were pregnancy-related bleeding, bleeding disorders, use of the intrauterine contraceptive device. By purposive sampling design, 100 women with AUB were selected after eligibility for inclusion and exclusion criteria. The questionnaire was used in the present study included the sociodemographic characteristics of the participants (age, occupation, and marital status), parity history, body mass index, smoking history, contraception history, drugs history (anti-coagulants and anti-thyroid), LMP frequency, menstrual bleeding patterns, post-coital bleeding, intermenstrual bleeding, thyroid-stimulating hormone level, triiodothyronine level, thyroxin level.

\section{Statistical analysis}

All characteristics were summarized descriptively. For continuous variables, the summary statistics of mean \pm standard deviation (SD) were used. For categorical data, the number and percentage were used in the data summaries and diagrammatic presentation. A Chi-square test was used as a test of association. Data were analyzed using SPSS software v.23.0 and Microsoft office 2007.

\section{RESULTS}

The maximum number of patients 42 (42\%) were belonged to the age group 31-40 years, followed by $32 \%$ of cases from the age group of 40 years and above. $15 \%$ of the cases were below the age of 20 years. Among the 100 cases, 37 were para $2(37.0 \%), 20$ cases were para3 $(20.0 \%)$, while 17 were unmarried $(17.0 \%)$, Nullipara constituted for about $7(7.0 \%)$ and remaining patients were with parity 4 or more.

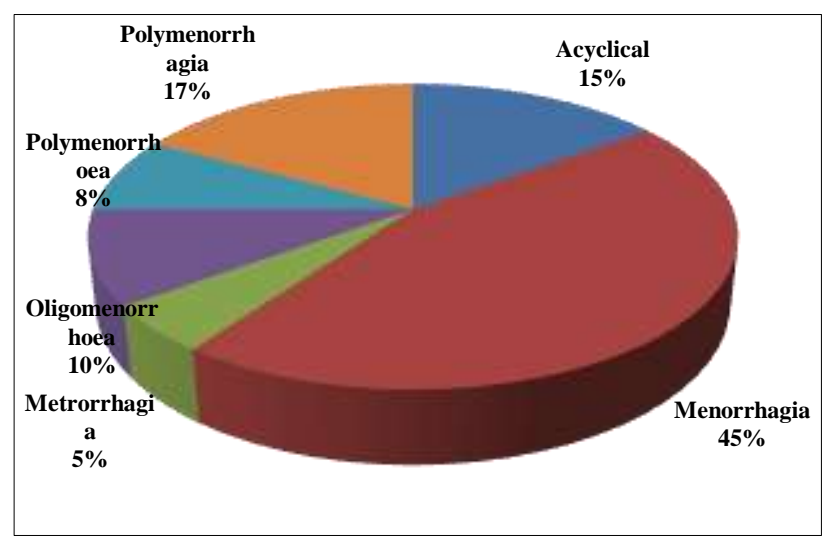

Figure 1: Distribution of menstrual irregularities.

Among various menstrual irregularities, the commonest was menorrhagia $45 \% .17 \%$ of the patients presented were found with polymenorrhagia. $15 \%$ of the patients had a cyclical bleeding.

Among the thyroid dysfunctions, the prevalence of subclinical hypothyroidism was $8 \%$, there were 2 hypothyroid and 1 hyperthyroid case among all cases. The total thyroid disorders associated with $11 \%$. 
Age-wise, below the age of 20 years, 13 cases were euthyroid, 2 had subclinical hypothyroidism. Among the cases belonging to 21-30 years, 10 cases were euthyroid and 1 had hypothyroidism. Among the age group of 31-
40 years, 38 patients were euthyroid, 1 had hypothyroidism and 3 had subclinical hypothyroidism. Above the age of 40 years, 3 patients had subclinical hypothyroidism and 1 had hyperthyroidism.

Table 1: Thyroid dysfunction in relation to parity.

\begin{tabular}{|c|c|c|c|c|c|c|}
\hline Parity & No. of cases & Euthyroid & Нypo & Sub clinical hypo & Hyper & TDF \\
\hline Un-married & 17 & 5 & & 2 & & 2 \\
\hline Nullipara & 7 & 7 & & & & \\
\hline Para 1 & 14 & 12 & 1 & 1 & & 2 \\
\hline Para 2 & 37 & 34 & 1 & 2 & & 3 \\
\hline Para 3 & 20 & 19 & & & 1 & 1 \\
\hline 4 or more & 5 & & & 3 & & 3 \\
\hline Total & 100 & & & & & \\
\hline
\end{tabular}

Chi-square $\mathrm{p}$ value $<0.001$.

Table 2: Bleeding pattern with thyroid dysfunction.

\begin{tabular}{|lll|llllllll|}
\hline Type & No. EU & Hypo & $\begin{array}{l}\text { Sub } \\
\text { hypo }\end{array}$ & Hyper & Total & $\%$ & $\begin{array}{c}\% \text { of } \\
\text { hypo }\end{array}$ & $\begin{array}{l}\% \text { of sub } \\
\text { hypo of }\end{array}$ \\
\hline Acyclical & 15 & 13 & 1 & 1 & 0 & 2 & $2 / 15(13.33)$ & $1 / 15(6.6)$ & $1 / 15(6.6)$ \\
hyper
\end{tabular}

Chi-square $\mathrm{p}$ value $<0.001$.

In patients belonging to the age group $<20$ years, polymenorrhagia was the most common bleeding pattern (33\%). In patients belonging to the 21-30 years age group, a cyclical bleeding appeared to the most common bleeding pattern $(45.45 \%)$. In patients belonging to the age group 31-40 years, menorrhagia was the most common bleeding pattern (50\%). In patients above 40 years of age, menorrhagia appeared to be the most common bleeding pattern (53.12\%).

Parity wise, among unmarried females, only 2 (11.7\%) patients had thyroid disorders. Among cases with parity $1-2,9.8 \%$ of patients had thyroid dysfunction. While cases with more than 3 parity, $16 \%$ case found with a thyroid disorder. The association between parity and thyroid dysfunction was found to be statistically significant $(\mathrm{p}<0.05)$.

Patients who presented with metrorrhagia have a prevalence of $20 \%$ of thyroid dysfunction, this appears to be the most common bleeding pattern according to the present study to be associated with thyroid disorders. Patients who presented with oligomenorrhoea had a $10 \%$ prevalence of thyroid disorder; their bleeding pattern appears to be the least common to be associated with thyroid disorders. Among hypothyroidism cases, metrorrhagia was present in $20 \%$ cases. Among subclinical hypothyroidism cases, Menorrhagia was present in $11 \%$ cases while Oligomenorrhoea was only bleeding pattern found among hyperthyroidism cases. The association between bleeding patterns with thyroid dysfunction was found to be statistically significant $(\mathrm{p}<0.05)$.

\section{DISCUSSION}

Abnormal uterine bleeding is accompanied by the low quality of life attributed to treatment efforts of bleeding and outcomes of high blood loss like fatigability and anemia. ${ }^{15}$ The endocrine disturbances play a major role in the pathogenesis of abnormal uterine bleeding. ${ }^{18}$ In this study, the most common AUB was menorrhagia (45\%) followed by polymenorrhagia $(17 \%)$. Fraser et al also included the polymenorrhagia and menorrhagia within the definition of abnormal uterine bleeding. ${ }^{19}$ Other studies found that menorrhagia as the most common type of AUB. ${ }^{20,21}$ The bleeding pattern in this study was significantly associated with AUB among participant women $(p<0.05)$. Similarly, Mohan et al documented that intermenstrual bleeding is a frequent presentation of abnormal uterine bleeding. ${ }^{22}$ Hormonal contraception was 
the major cause of AUB among women in the reproductive age period. ${ }^{23}$

In the study, most of the women were in the age group 31-40 years. A similar study done by Mohapatra $\mathrm{S}$ et al reported that the highest incidence of AUB was seen in the age group 30-39 years (39\%). ${ }^{24}$ Parveen $\mathrm{M}$ et al also observed that majority of the women were in the age group between $30-39$ years $(44 \%){ }^{25}$ Similar results were found in the study. ${ }^{26-28}$ The complaint of heavy menstrual bleeding $(45 \%)$ was the most common pattern of AUB. It was followed by heavy menstrual bleeding with shortening of the menstrual cycle which was seen in $17 \%$ of women. Parveen et al also found an incidence of $45 \%$ of heavy menstrual bleeding in their study. ${ }^{25}$ Women with complaints of shortened cycles were $5 \%$ which was similar to in the study by Verma et al and Parveen et al. ${ }^{25,29}$

Thyroid disorders are common in females with subclinical hypothyroidism as it's the most common type. Menstrual irregularities are seen in both hyperthyroidism as well as hypothyroidism. This study showed that hypothyroidism constitutes $11 \%$ of women with AUB and hyperthyroidism did present in $1 \%$ of them. These findings are a little higher than the results of previous Iraqi study conducted by Al-Hakeim which found that among women with menstrual disturbances, hypothyroidism present in $16.1 \%$ of them and hyperthyroidism was present in $3.4 \%$ of them. ${ }^{30}$ This difference in thyroid dysfunction between two studies might be due to geographical variation and high prevalence of thyroid disorders in Kurdistan. $11.1 \%$ of women with thyroid dysfunction presented with menorrhagia. These results were comparable to the results of the study done by Maria JD ET al. ${ }^{31}$ Results were similar to other studies. ${ }^{32,33}$

The present study showed a significant association between women with AUB and hypothyroidism $(p=<0.001)$. This finding is similar to the results of many previous studies. ${ }^{24,26}$ Whitaker et al documented the hypothyroidism is one of the common diseases that must be assessed among women with abnormal uterine bleeding. ${ }^{33}$ The prevalence of hypothyroidism was reported high in Iraq, specifically in the Kurdistan region. ${ }^{30}$ The mechanism by which the hypothyroidism can affect the menstrual cycle is not fully understood. However, some authors attributed this relationship to irregular or no ovulation that decreases the luteinizing hormone and elevating the estrogen leading to menstrual bleeding. ${ }^{33}$

\section{CONCLUSION}

Abnormal uterine bleeding is strongly associated with thyroid-related disorders. Any abnormality in the menstrual cycle can be a possible presenting symptom of thyroid disorders, thus thyroid function tests must be evaluated in them. It can lead to early diagnosis as well as treatment preventing unnecessary surgical interventions. Thyroid dysfunction is a common cause of abnormal uterine bleeding among reproductive-age women. The menorrhagia and polymenorrhagia are the prevalent bleeding types. Thyroid hormone assessment should be taken into consideration in the assessment of women with abnormal uterine bleeding.

Funding: No funding sources

Conflict of interest: None declared

Ethical approval: The study was approved by the Institutional Ethics Committee

\section{REFERENCES}

1. Devi J, Aziz N. Study of histopathological pattern of endometrium in abnormal uterine bleeding in the age group 40-60 years. A study of 500 cases. Int J Med Sci Clinic Invent. 2014;1:579-85.

2. Padubidri VG, Daftary SN. AUB. In: Padubidri VG, Daftary SN, eds. Shaw's Textbook of Gynecology. $16^{\text {th }}$ ed. USA: Elsevier Health Sciences; 2015:335348.

3. Munro MG, Critchley HO, Fraser IS. The FIGO systems for nomenclature and classification of causes of abnormal uterine bleeding in the reproductive years: who needs them? Am J Obstet Gynecol. 2012;207(4):259-65.

4. Hassan FF. The Frequency of histopathological patterns in endometriam obtained from a sample of iraqi women with abnormal uterine bleeding. Karbala J Med. 2017;10(3):3846-56.

5. Ajmani NS, Sarbhai V, Yadav N, Paul M, Ahmad A, Ajmani AK. Role of thyroid dysfunction in patients with menstrual disorders in tertiary care center of walled city of Delhi. J Obstet Gynaecol India. 2016;66(2):115-9.

6. Faisal AH. Study of thyroid hormones among female Iraqi thyroid disorders. In The $2^{\text {nd }}$ Annual Int Conf Northeast Pharma Res Thailand. 2010;2:250-5.

7. Pahwa S, Gupta S, Kaur J. Thyroid dysfunction in dysfunctional uterine bleeding. J Adv Res Med Sci. 2013:5(1):78-83.

8. Bhavani N, Sathineedi A, GiriA, Chippa S, Reddy VSP. A study of correlation between abnormal uterine bleeding and thyroid dysfunction. J Recent Trends Sci Technol. 2015;14(1):131-5.

9. Byna P, Siddula S, Kolli S, Shaik MV. Thyroid abnormality in perimenopausal women with abnormal uterine bleeding. Int $\mathrm{J}$ Res Med Sci. 2015;3(11):3250-3.

10. Mansourian AR. Female reproductive physiology adversely manipulated by thyroid disorders: A review of literature. Pak J Biol Sci. 2013;16(3):11220.

11. Sharma N, Sharma A. Thyroid profile in menstrual disorders. JK Sci. 2012;14(1):14-7.

12. Al-Naffii KO, Nasseralah CABM HAA, Al-Hillali KA, Ali AFM. Hypothyroidism in adults early 
clinical presentation in relation to age. Karbala $\mathbf{J}$ Med. 2008;2(3):352-6.

13. Al-Bustany DA. Clinical study of cases with hyperthyroidism in Erbil Governorate, Kurdistan Region-Iraq. Zanco J Med Sci. 2011;15(1):6-12.

14. Liu Z, Doan QV, Blumenthal P, Dubois RW. A systematic review evaluating health related quality of life, work impairment and health care costs and its utilization in abnormal uterine bleeding. Value Health. 2007;10(3):183-94.

15. Deshmukh PY, Boricha BG, Pandey A. The association of thyroid disorders with abnormal uterine bleeding. Int $\mathbf{J}$ Reprod Contracept Obstet Gynecol. 2015;4(3):701-8.

16. Schrager S. Abnormal uterine bleeding associated with hormonal contraception. Am Fam Physician. 2002;65(10):2073-80.

17. Attia AH, Youssef D, Hassan N, El-Meligui M, Kamal M, Al-Inany $\mathrm{H}$, et al. Subclinical hyperthyroidism as a potential factor for dysfunctional uterine bleeding. Gynecol Endocrinol. 2007;23(2):65-8.

18. Kang JH, Kueck AS, Stevens R, Curhan G, Vivo DI, Alexander E, et al. A large cohort study of hypothyroidism and hyperthyroidism in relation to gynecologic Cancers. Obstet Gynecol Int. 2013;743721.

19. Fraser IS, Critchley HO, Broder M, Munro MG. The FIGO recommendations on terminologies and definitions for normal and abnormal uterine bleeding. Semin Reprod Med. 2011;29(5):383-90.

20. Muttappallymyalil J, Sreedharan J, Al Biate MA, Mummigatti K, Shantakumari N. Prolactin level in women with abnormal uterine bleeding visiting department of obstetrics and gynecology in a university teaching hospital in Ajman, UAE. Gulf Med J. 2014;3(S2):S91-8.

21. Marimuthu K, Loganathan M. Influence of thyroid gland in women with abnormal uterine bleeding in reproductive age group. Int $\mathrm{J}$ Reprod Contracept Obstet Gynecol. 2017;6(6):2222-5.

22. Mohan S, Page LM, Higham JM. Diagnosis of abnormal uterine bleeding. Best Pract Res Clin Obstet Gynaecol. 2007;21(6):891-903.

23. Gulab K, Monika S, Nidhi S, Rinki H, Rahul K, Juber A. Hypothyroidism-a risk factor for menstrual disorders among nulliparous females. IOSR J Dent Med Sci. 2015;14(12):78-81.

24. Mohapatra S, Behera SK. Prevalence of hypothyroidism in patients with provisional diagnosis of DUB. IJOG. 2017;3(1):23-9.

25. Parveen M, Kumari S, Haque SS, Kumar R. Evaluation of thyroid profile status in women with abnormal uterine bleeding in north Indian population. Int J Biomed Adv Res. 2017;8(7):28891.

26. Al Shahrani AS, El-Metwally A, Al-Surimi K, Salih SB, Saleh Y. The epidemiology of thyroid diseases in the Arab world: a systematic review. J Public Health Epidemiol. 2016;8(2):17-26.

27. Jawzali JI. Regional differences of drinking water iodine and its association with thyroid disorder and serum iodine. Med J Babylon. 2017;14(1):198-208.

28. Vinita S, Ashwini SN. Impact of thyroid disorders on menstrual function. Fogsi Focus. 2006;1:30-1.

29. Verma SK, Pal A, Jaswal S. A study of thyroid dysfunction in dysfunctional uterine bleeding. Int $\mathbf{J}$ Reprod Contracept Obstet Gynecol. 2017;6(5):20359.

30. Al-Hakeim HK, Jassim WE, Ali IA. Prevalence of endocrine disorders among iraqi women with menstrual disturbances. Karbala J Med. 2010;3(3):889-96.

31. Maria JD, Jayakumari S, Sundaram PS. A Prospective study on hypothyroidism in premenopausal women. Int $\mathbf{J}$ Pharm Sci Rev Res. 2016;39(1):183-7.

32. Pushpa S, BikhaRam D, Razia MA, ZulfiquarAli SS, Tarachand D, Ishrat B. Impaired thyroid functions in patients with menstrual disturbances (An experience of a private clinic). World Appl Sci J. 2009;7(4):53842.

33. Whitaker L, Critchley HOD. Abnormal uterine bleeding. Best Pract Res Clin Obstet Gynaecol. 2016;34:44-65.

Cite this article as: Shawl AS, Naz M. Association between thyroid disorders and abnormal uterine bleeding in reproductive ages. Int $\mathrm{J}$ Reprod Contracept Obstet Gynecol 2020;9:3580-4. 